\title{
GROWTH IN AMBLYSTOMA PUNCTATUM DURING THE EMBRYONIC AND EARLY LARVAL PERIOD
}

\author{
W. T. DEMPSTER \\ Department of Anatomy, University of Michigan \\ EIGHT HTURES
}

In a previous article, the increase in weight and length of embryos and larvae of Amblystoma punctatum $[=$ Ambystoma maculatum] was studied from animals living under natural conditions (Dempster, '30). Weight changes from the segmenting eggs to the period of metamorphosis could be described by a single sigmoid growth curve. The curves representing changes in length were not as simple as those dealing with weight. During the free-living period, it is true, the changes in length followed the sigmoid curve to metamorphosis [this is evident both from the above study and from the curves ( $\mathrm{B} \& \mathrm{C}$, p. 9) of Harrison ('29) on laboratory animals; the curve by Stone ('30) will allow similar interpretation]. During the earlier embryonic period, the changes in length must be considered differently. Patch ('27) has described two periods of sigmoid linear increment previous to metamorphosis, one in the embryonic and the other in the larval period. Two phases were likewise found in natural conditions (Dempster, '30). No explanation of the difference between the curves of the one- and of the threedimensional measurements has been advaneed.

The primary object of the present communication is further investigation of growth during the period of early development, involving the study of a uniform stock of animals under constant environmental conditions. The data presented here, along with the data in the literature upon the older specimens will probably allow certain generalizations on the gross increment of the salamander during its whole aquatic period. 


\section{PROCEDURE}

The eggs and embryos used in the study were collected from a forest pond near Ann Arbor, Michigan, and brought to the laboratory where the egg clutches were teased apart. The individual eggs in their capsules were separated from the surrounding jelly matrix. Since eggs, seen through their vitelline membranes, varied in diameter, roughly from 1.9 $\mathrm{mm}$. to $2.5 \mathrm{~mm}$., it was essential that they be selected for size. Clutches in which the diameter across the superior pole of the eggs at the 1-cell and 2-cell stages did not average $2.2 \pm 0.03 \mathrm{~mm}$. were discarded. The eggs of selected clutches, placed in glass jars (9 or 15 sq.in. bottom area) containing 3 inches of filtered pond water, were subjected to a constant temperature in a bath regulated to $20^{\circ} \pm 0.5^{\circ} \mathrm{C}$.

At intervals, once or twice daily, a random sample of ten specimens was taken from each jar and, after the egg capsules were removed, diameters were determined. The mean diameter of the sample was ascertained and the specimens were classified according to the stage number of Harrison's Normal Tables. ${ }^{1}$ The interval in hours between successive measurements was recorded. Eggs and embryos were measured during the early stages bp the use of a Greenough microscope having a camera lucida over one eyepiece. By means of the camera lucida, the image of a calibrated scale, lying on the work-table, was superimposed on that of the specimen. When the specimens became motile, they were given a light ether anaesthesia and measured with drafting calipers and a millimeter scale. Individual measurements were estimated to the nearest tenth millimeter. The data on linear measurements, involving slightly more than 4000 records, did not necessitate the death of animals. Time and again, previously measured specimens formed part of a subsequent sample.

\footnotetext{
${ }^{1}$ The figures of Harrison's tables on the development of Amblystoma punctatum (unpublished), a copy of which was kindly supplied to me, have formed an indispensable standard for differentiating embryos of one stage from another. These tables consist of illustrations of forty-six stages of development from the 1-cell stage to that in which yolk had been absorbed and the animal was feeding actively.
} 
Since the time interval between fertilization and the first cleavage was undetermined, the age found (and indicated in the various graphs) was reckoned from the time of the first cleavage. The records obtained from the procedure listed above gave average length of each stage, time between stages, and age from the first cleavage division. Occasionally, when freshly collected specimens corresponded in length and stage with the average length and stage of experimental animals, they were placed in the constant-temperature bath, and data obtained from these were used to supplement data provided by the original specimens.

Ninety samples, at various stages of development involving about 3200 animals, were taken for determinations of weight and volume. After removal of the individual egg capsules, the sample was placed in a pycnometer consisting of a widemouth 6-ce. capacity 'ointment jar,' whose rim, ground perfectly flat, could be covered hermetically by a flat glass disc. This jar containing the specimens was filled with distilled water and the cover put in place, care being taken to avoid bubbles. Water was absorbed from the space between the cover and the jar rim by filter paper until cohesive forces held the cover to the jar. In this way the same volume of specimens and water was obtained at each measurement. Successive weighings of the pycnometer filled with distilled water showed that the mass of contained fluid varied only $2 \mathrm{mg}$. Four weighings were made, namely, A) the dry pycnometer, B) pycnometer filled with water, C) the pycnometer filled with the specimens and water, and, D) the pycnometer and the specimens (water having been removed by pipette and filter paper). The volume and live weight were obtained from these data: $($ Vol. $=(\mathrm{B}-\mathrm{A})-(\mathrm{C}-\mathrm{D})$; Mass $=(\mathrm{D}-\mathrm{A})$. After this series of weighings, the specimens were dehydrated at a temperature of $50^{\circ} \mathrm{C}$. in a waterbath paraffin oven and then in a desiccator jar containing sulphuric acid. Determinations of dry weight were then made. 


\section{CHRONOLOGY OF CHANGES IN FORM}

After separation of the individual eggs from the jelly matrix of the clutch, the eggs were still surrounded by two envelopes, an outer capsule having a complex lamellated structure (described by Piersol, '29) and an inner closely applied vitelline membrane. As development proceeded, the volume of fluid within the envelopes increased, due to absorption of fluid from the surrounding medium. The vitelline membrane ruptured 85 to 90 hours after the first cleavage while the embryo was a late neurula. The outer capsule persisted for some time, but it also became swollen and ruptured liberating the young swimming larva. The rupture of this capsule (hatching) occurred about 350 hours after the 2-cell stage.

No attempt will be made here to depict the form of embryos, since this has been done in part by Clarke (1880), Eycleshymer (1895), and Wilson (1897) and in more detail by the figures of Harrison's Normal Tables. The time relationships during development of the more significant stages were determined and some of these are indicated in the following table:

\begin{tabular}{|c|c|c|}
\hline STAAGE & $\begin{array}{l}\text { STAGE-NUMBHR } \\
\text { OF HARRIBON }\end{array}$ & $\begin{array}{c}\text { TIME FROM FIRST } 1 \\
\text { CLEAVAGE (HOURS) } \\
\text { AT } 20^{\circ} \mathrm{C} \text {. }\end{array}$ \\
\hline First eleavage & 2 & 0 \\
\hline Second cleavage & 3 & 2 \\
\hline Third cleavage & 4 & 4 \\
\hline Fourth cleavage & 5 & 6 \\
\hline Fifth cleavage & 6 & 8 \\
\hline Sixth cleavage & 7 & 12 \\
\hline Blastula & 8 & 17 \\
\hline Gastrula & 9 & 34 \\
\hline Yolk plug & 11 & 52 \\
\hline Neural folds & 14 & 69 \\
\hline \multirow[t]{2}{*}{ Neurula } & 15 & 75 \\
\hline & 18 & 89 \\
\hline Head process & 23 & 114 \\
\hline Tail bud & 25 & 128 \\
\hline Gill bud-balancer & 36 & 214 \\
\hline Tail fin & 37 & 246 \\
\hline Anterior limb & 38 & 289 \\
\hline Two toes & 42 & 440 \\
\hline Three toes & 45 & 567 \\
\hline Eating & 45 & $580 \%$ \\
\hline Yolk gone & 46 & 607 \\
\hline
\end{tabular}

\footnotetext{
1 The ages indicated in the table are those obtained by three point smoothing of data in which the 'probable error' of the age was between 2 to 5 per cent of the mean elapsed time since the first cleavage.
} 
Wilson (1897) has tabulated (in part from Eycleshymer) a few time relations of developing specimens at room temperature:

$\begin{array}{ll}\text { Fertilization to first cleavage, } & 10 \text { hours } \\ \text { Time of each of first five cleavages, } & 105-110 \text { minutes } \\ \text { Beginning of gastrulation, } & 60 \text { hours } \\ \text { End of gastrulation, } & 78 \text { hours } \\ \text { Appearance of external gills, } & 19 \text { days } \\ \text { Hatching, } & 18-21 \text { days } \\ \text { Assumption of adult characters, } & 100 \text { days }\end{array}$

According to Harrison ('29), metamorphosis occurred 120 days after the tail-bud stages (age, 5 to 7 days) for animals which were poorly fed, in 100 days with better feeding, and in 58 days with maximum feeding (data of Twitty and Schwind).

Under natural conditions in the pond habitat studied by the author, hatching occurred in 38 days in 1928, and in 41 days in 1929. In these years metamorphosis occurred in 152 and 141 days, respectively.

Differences in growth rate may be explained, in part, at least, by two factors.

An increase in temperature speeded up the growth process, while a thermal decrease in the surrounding medium caused a slowing in developmental rate. The change in rate due to the thermal factors is suggested by the following thermal coefficients, determined from specimens which developed in media which varied within $\pm 1^{\circ} \mathrm{C}$. from the temperature indicated:

$\begin{array}{rr}{ }^{\circ} \mathrm{C} . & Q_{10} \\ 4-13 & 1.4 \\ 13-19 & 3.2 \\ 19-27 & 4.7\end{array}$

Embryos grown at different temperatures, however, did not appear identical at equivalent stages. Difference in curvature of the axis during the pre-motile stage, in the amount of belly yolk, and in gill development were apparent in specimens living at the four different temperatures.

Further, if eggs remained embedded in the jelly matrix, they develop somewhat more slowly than they would other- 
wise. Eggs in the interior of the mass developed more slowly than those at the periphery. This was presumably due to an inefficient respiratory exchange through the jelly mass causing a slowing of metabolism. This, in turn, affected the growth rate. Under actual pond conditions, this mechanism probably had a survival value to the species. If animals were distributed through a number of stages of development, more would survive a temporary unfavorable change in environment than would be expected if all were at a particular critical stage of development.

\section{CHANGES IN VOLUME}

As mentioned above, the Amblystoma egg is surrounded by a transparent vitelline membrane for about the first 85 hours of its development. The membrane is so renitent and the egg so soft that removal of the membrane was an impractical procedure. Consequently, the actual changes in volume, and in other characters to be treated later, were veiled during the period of the presence of the membrane.

As development proceeded, water was absorbed through the membrane and the volume of the whole system-egg, membrane, and included fluid-showed an increment which gradually increased to about 10 cu.mm. When the vitelline membrane ruptured, the volume, now that of the egg alone, returned to a value approximating that of the egg within its membrane at the time of the early cleavages (fig. 1).

As development proceeded from the neurula stage, the increment in volume was at an increasingly rapid rate (to about 24 cu.mm.). 'This is expressed graphically by a curve concave to the age axis. The curve refers to a system, it may be pointed out, in which yolk is decreasing, and protoplasm is increasing through the conversion of yolk and the addition of water. If yolk could be eliminated in measurements, it seems likely that a similar but steeper curve would be produced.

After the yolk had been used and if food was withheld, the animals decreased in volume almost as quickly as previously 
they had increased. After a few days, the animals died of starvation. If, on the other hand, food was supplied and the animals were allowed to feed as they did under natural conditions, growth followed a sigmoid type of increment to metamorphosis. The increment before feeding obviously was a part of the early phase of sigmoid growth.

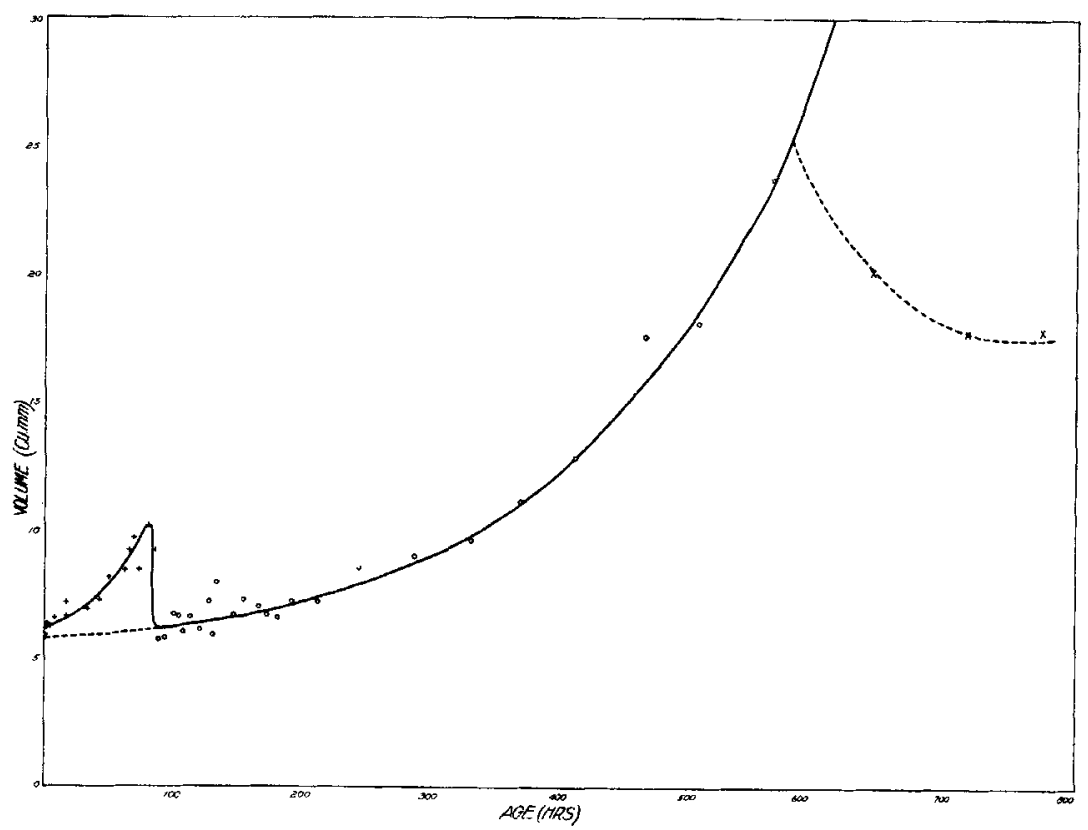

Fig. 1 Curve showing increase in volume of Amblystoma punctatum during the first 25 days of development and the decrease in volume (dotted lines) under conditions of inanition. Values during the presence of the vitelline membrane are indicated by +'s and do not represent actual embryo quantities.

Clearly, there is no evidence given by volume changes during the early period to suggest any deviation from the sigmoid curve characterizing the whole aquatic period.

RELATION OF WEIGHT AND VOLUME

A curve of weight-to-age shows much the same changes as the volume-to-age curve. The significant difference being that there was less change in mass during the first 200 hours. The 
change in density which was responsible for this difference in the curve is clearly shown by plotting density-to-volume (fig. 2).

After the vitelline membrane had disappeared, the density had a value of about 1.16. As the volume increased, density followed a hyperbolic curve, showing an initial marked decrease, and later, a very slight diminution. The elbow of the curve is represented by data from specimens which have almost reached the hatching stage.

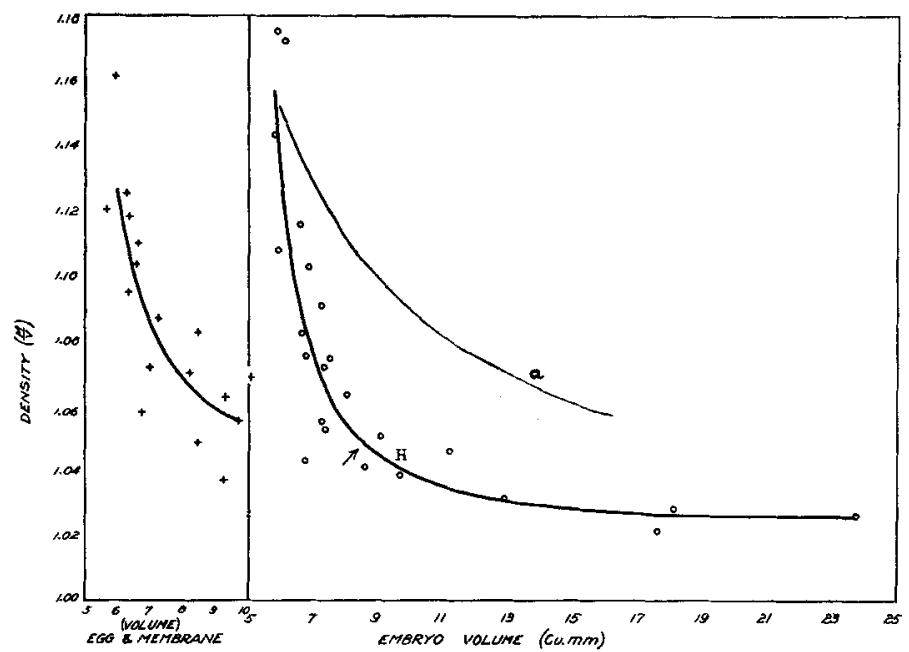

Fig. 2 Curves showing decreasing density of A. punctatum. In the right-hand curve, the arrow designates the 'elbow' of the curve; hatching occurs at $H$. Curve $a$ indicates the decrease in density to be expected if the eggs increased through the simple addition of water.

It is of interest to compare the curve obtained from the salamander eggs with that (curve $a$, fig. 2), which would represent the decrease in density of the egg, if the only change, in a physical sense, were the simple addition of water. Curve $a$ represents the density change of an inorganic substance having the same density as the egg, dissolving in various quantities of water, but entering into no special type of union with the water. In contrast with this type of density decrease, the volume of an egg increased at a more rapid rate 
than the mass during the initial phase of density change. This will be due either to more dense materials leaving the egg, to a reorganization of colloidal properties of the egg and embryo, or to both. The likelihood of the former process is suggested by the study of Adolph ('27) on frog embryos subjected to hypertonic and hypotonic fluids where it is stated that fertilization "enables electrolytes to get out of the eggs . . . . Before hatching, the ability of the embryo to hold its electrolytes is regained and the ability to absorb solutes from a medium very dilute in them is acquired." Since the density of the dry weight ${ }^{2}$ does not seem to change before hatching and the loss in dry weight is slight, it seems unlikely that a loss in electrolyte alone would account for the decrease in density found. A reorganization, possibly involving changing relations of bound and free water (Gortner, '32), will probably have to be sought before an explanation can be given.

During the later phase of density change, the diminution in density may be accounted for by the decrease due to absorption of water.

\section{WATER AND DRY WEIGHT}

If the relative water content and dry weight be plotted in relation to age (fig. 3), it will be seen that, except for the period when the vitelline membrane was present, there was a constant increase in the percentage of water from 63 per cent to 92 per cent. From this point the water content decreases at a constant rate of 85 per cent at metamorphosis (Dempster, '30).

The dry weight decreased (fig. 4) 20.4 per cent by the time the yolk had disappeared. The decrease appears to be directly proportional to time; the loss of original mass of the egg due to metabolic processes was $8.33 \times 10^{-4} \mathrm{mg}$. per hour.

During the period of inanition the maintenance of the body was at the expense of 2.16 per cent of the dry weight or 2.79 $\times 10^{-3} \mathrm{mg}$. per hour.

\footnotetext{
${ }^{2}$ Density $==\frac{\text { Dry weight }}{\text { Live vol. }- \text { vol. } \mathrm{H}_{2} \mathrm{O} \text { lost by dehydration }}$.
} 


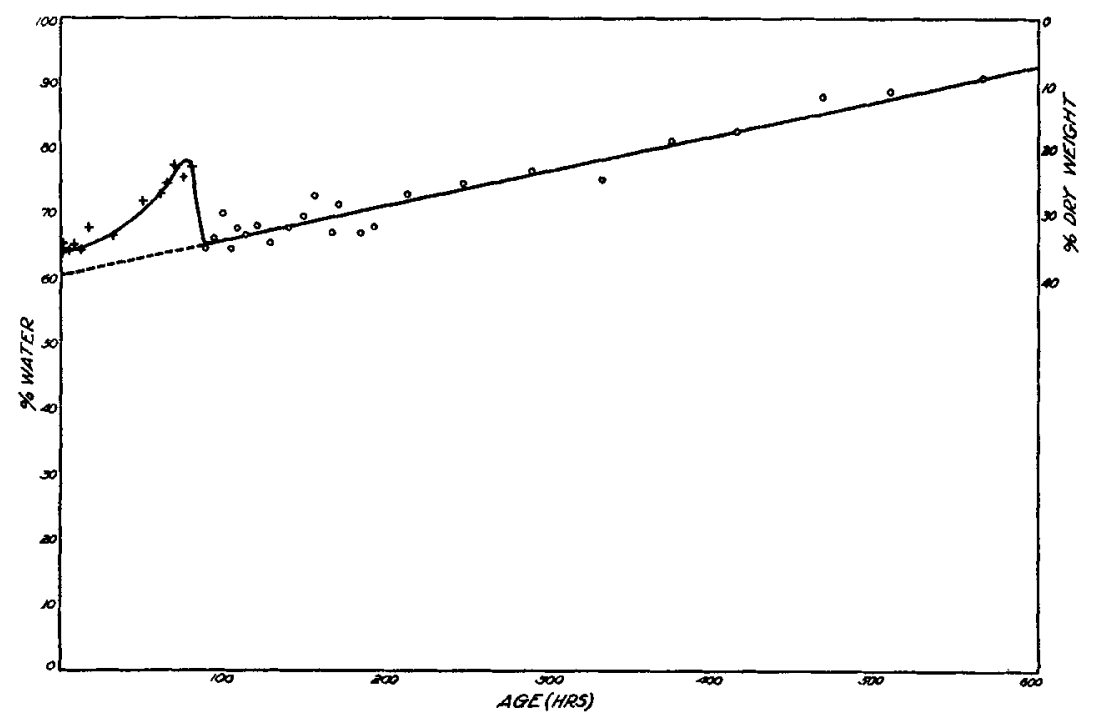

Fig. 3 Curve showing the proportion of water and dry substance in $A$. punctatum of different ages.

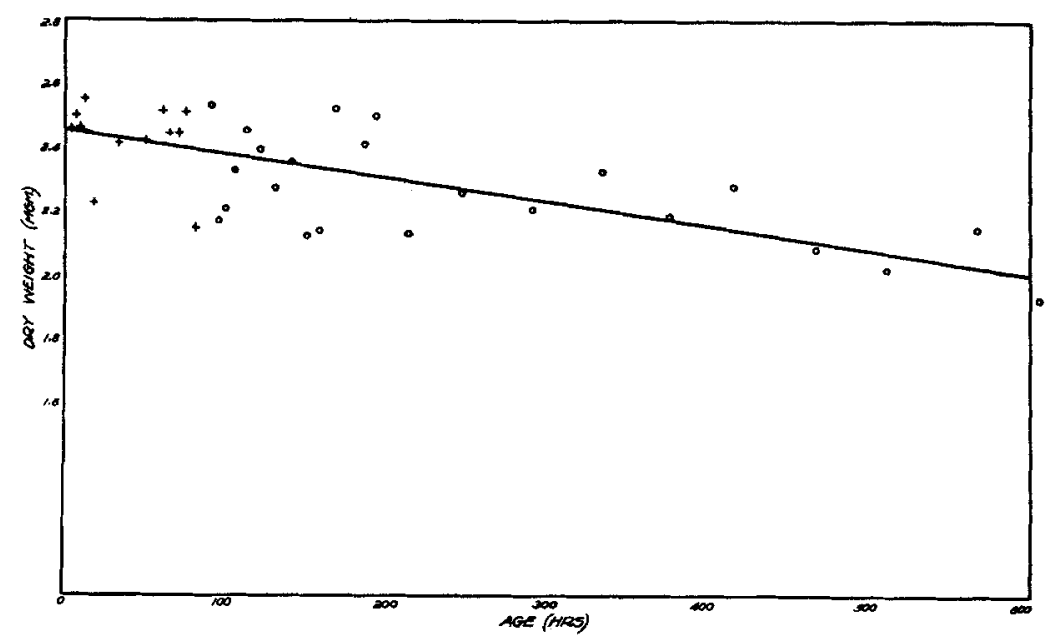

Fig. 4 Curve showing decrease in dry weight in relation to age. 


\section{LENGTH CHANGES}

When length is plotted against age, it is clear that the rate of linear increment is not constant (fig. 5). There were six distinctly delimited phases of linear increment and these were definitely correlated with the form of the embryo. The phases of growth were as follows: a) during the cleavage, blastula,

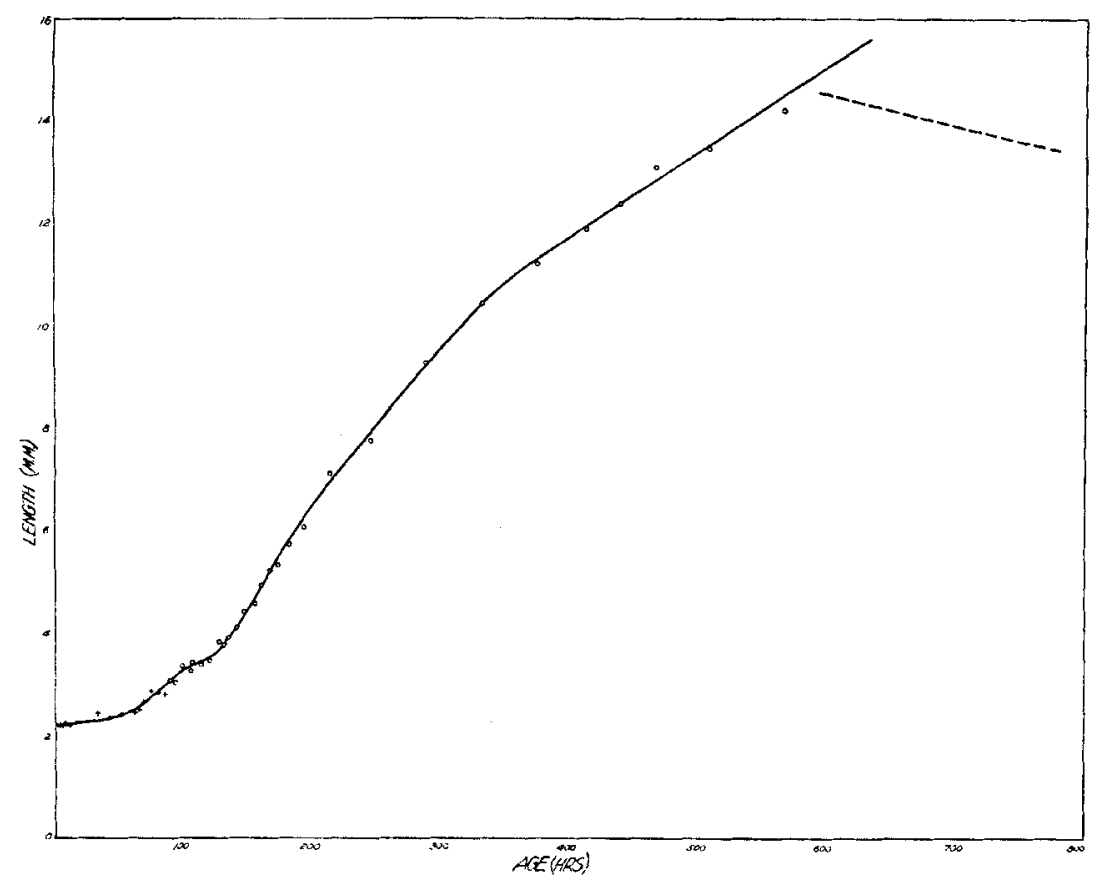

Fig. 5 Curve showing linear increment in relation to age, and the decrease in length (dotted line) during the starvation period.

gastrula, and yolk-plug stages there was only a slight increase in the diameter of the spheroidal embryo. The linear increase became more rapid, $b$ ) when the medullary folds formed and closed. A third period of increase, $c$ ) this being very slow, was evident during the formation of the head and tail processes. The embryonic axis, instead of being straight, was quite curved at this period. This was followed by a period, $d$ ) of more rapid increase as the curved axis became straightened. 
Growth continued at a slightly less rapid rate, $e$ ) to the hatching period. After hatching, the length increased more slowly, f) up to the time when food was required. This sixth phase of increment normally continued as the sigmoid curve characteristic of larval growth (Harrison, '29; Dempster, '30). When the animals had utilized the yolk supply and were unfed, they decreased in length and soon died of inanition. Presumably, if the embryonic axis were straight throughout,

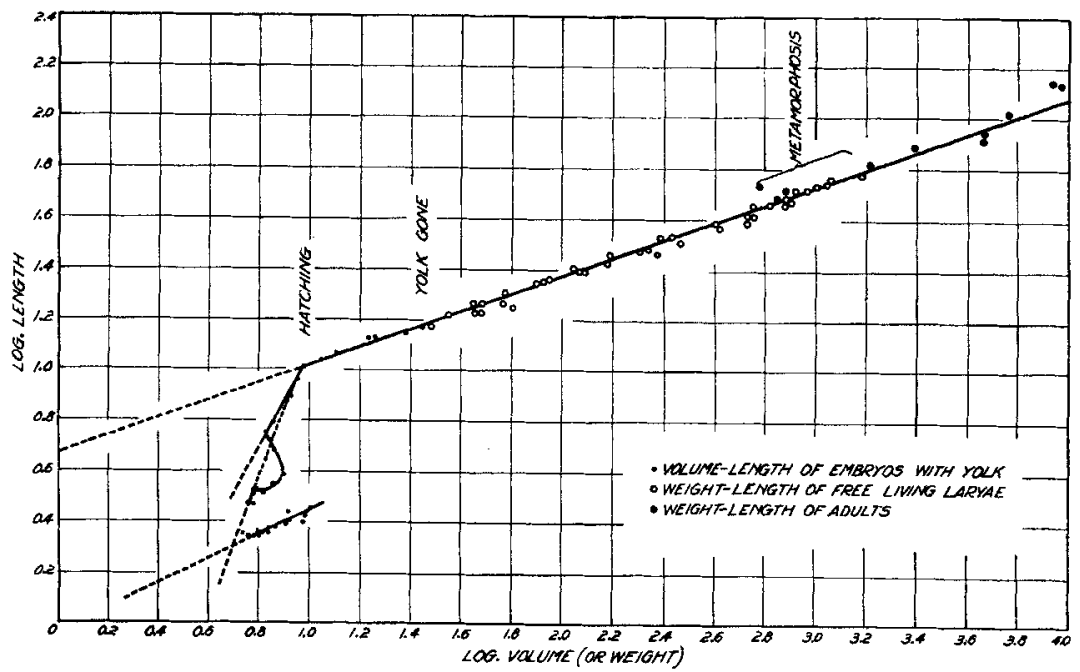

Fig. 6 Curve showing log. length and log. volume (log. weight in the older stages) of A. punctatum. Dotted lines refer to the calculated curves.

or if the curved axis could be measured accurately, the third, fourth, and fifth phases of increment would be, in reality, one.

\section{RELATION BETWEEN LENGTH AND VOLUME}

When the logarithms of length and of weight were plotted (fig. 6) it was evident that, after hatching, there was a direct relationship between the two factors. This relation appeared to hold for adults as well as for the larval forms. In the preiod before hatching the somewhat irregular curve may be approximated by different straight lines. If the slope and constant are computed, the curves may be described by a 
formula, $\mathrm{L}=\mathrm{kW}$; where $\mathrm{L}$ is the length, $\mathrm{k}$ is a constant of form, $W$ is the weight or volume, and the exponent ${ }^{\text {a }}$ indicates the constant ratio of length to weight.

The factors during the periods of development are:

$\mathbf{k}=0.930, \mathrm{a}=0.452$ during the period of the vitelline membrane;

$\mathrm{k}=0.035, \mathrm{a}=2.51$ during the late neurula, and roughly for the period before hatching;

$\mathrm{k}=0.185, \mathrm{a}=1.769$ during the period (before hatching) of straightened body axis;

$\mathrm{k}=4.69, \mathrm{a}=0.349$ during the larval period (after hatching) and the adult period.

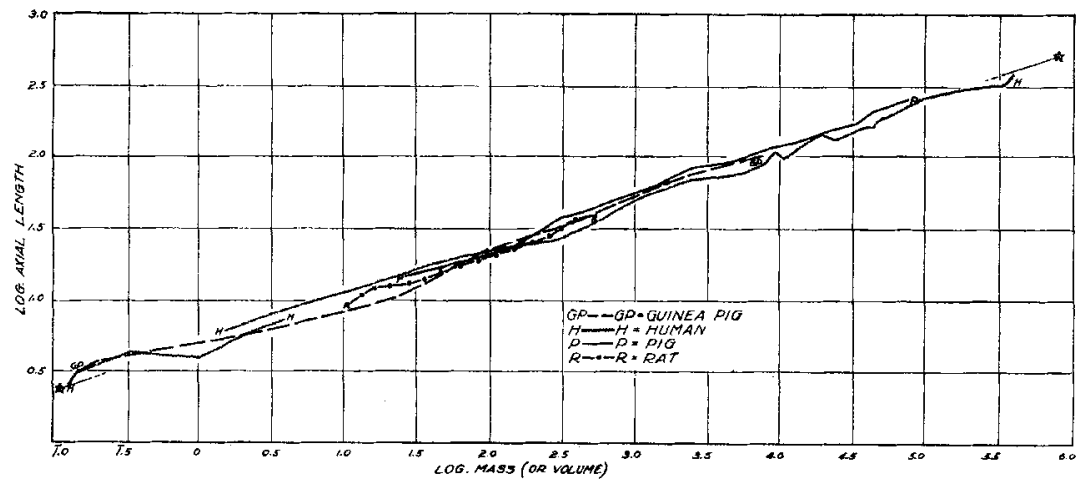

Fig.7 Curves (log, length to log. mass) representing the embryonic development of four species of mammal. A line between the two asterisks represents the relation between length and volume of a rectangular box with dimensions in the proportion 1: 1:11.

\section{RELATIONS IN OTHER ANIMALS}

The significance of the factors is suggested when the logarithms of weight and length for other developing animals are plotted as in figures 7 and $8 .^{3}$ It is seen that the bulk of the data tends to fall in the same line-essentially that (between the asterisks to the left and to the right of the

${ }^{3}$ The data which are plotted in figures 7 and 8 include that of Schaper ('02) on the frog and a group of data quoted by Needham ('31): Trout from Scheminski and Gauster; Gray; Kronfeld and Scheminski; grass snake from Bohr; rat from Stotsenberg; guinea-pig from Draper; pig from Lowrey; human from Jackson. The data of MeDowell, Allen, and MeDowell on the mouse; of Chaine, 3 of Fehling, Lockhead, and Cramer on the rabbit, and of Leberton and Schaffer on the pig (not plotted) are similar to those of the other mammals. 
graphs) represented by the increment in length and volume of a rectangular box having the proportions of $1: 1: 11$. In other words, despite changes in shape and form during the development of an animal, the relation of axial length to volume or weight (ignoring the slight deviation due to density) tends to be that which would be expected if there were no changes in form. Thompson ('17) has emphasized that a change in form nullifies the relation $\mathrm{W}=\mathrm{kL}^{3}$, yet here there is evidence which reveals a compensatory factor in the animal body for regulating length and volume. Somewhat closer inspection will reveal that in some animals data suggest that

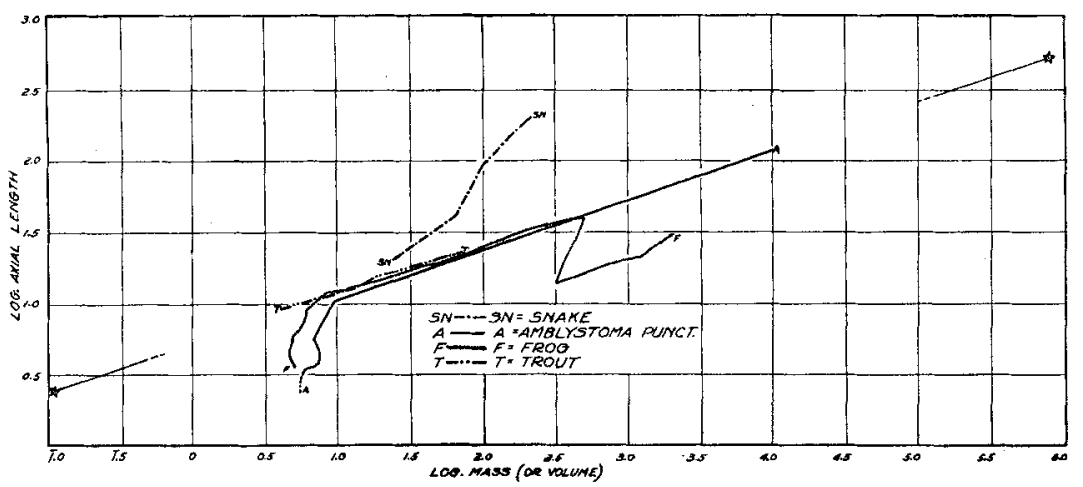

Fig. 8 Curves (log. length to log. mass) representing form relationships in trout, salamander, frog, and snake. Asterisks are the same as in figure 7 .

length may increase slightly more than would be expected from this generalization (compare the exponent 0.349 of the salamander data with that of the regular object, 0.333). These differences may be significant, but, with the data at hand, it is unwise to do more than call attention to this possibility.

Deviation is evident in the early stages of both the frog and the salamander (fig. 8). In these forms the variation is evidence of a larger mass in the early embryos than in older forms. Obviously, this is due to the yolk accumulation in the egg and early embryo. If it were possible to separate the yolk from the embryo, it is conceivable that the lengthvolume relationships might be similar to other forms. When 
the yolk was separated from the trout embryo before weighing, this typical relationship was evident.

It must be assumed, then, that the yolk is a factor in the amphibian egg, as Needham has continually stressed, which obscures the normal growth tendencies as indicated in other animals. After hatching, although some yolk is still present in the frog and salamander, it causes no deviation in the length-volume relations.

In the curves of figure 8 , it will be seen further that in the snake embryo, as contrasted with other animals, the growth in length is proportionately greater than that in weight. In the frog the changes of metamorphosis cause a marked difference in the growth characteristics of length and mass; it is not so in the salamander. During the larval condition, weight and volume relationships are as in other animals; metamorphosis induces a change. Thereafter, although length and mass increase proportionately, the adult axis is shortened and the factor or index of form has changed.

\section{SUMMARY}

1. There is no evidence of more than one phase of sigmoid growth in volume or mass for the aquatic stage of Amblystoma punctatum. The pre-feeding phase of increment is dealt with here.

2. The density of the egg decreases from 1.16 during development. Till a short time before hatching, the decrease (to 1.05) is very rapid. Thereafter, until all the yolk is gone, the decrease in density from 1.05 to 1.02 is slow. The decrease is not accounted for simply by the decrease in density due to the addition of water.

3. There is a constant gradual increase in percentage of water from 63 per cent to 92 per cent to the time when the larva begin feeding.

4. Of the amount of organic and mineral material present in the egg at time of its deposition, 20.4 per cent is used for metabolic processes. The remainder is represented by the dry weight of the larvae at the time it begins to feed. 
5. After this period, when deprived of food, the animals show a decrease in live weight, dry weight, and length, but the factors of length-volume relationship and the percentage water content do not change during the starvation period.

6 . The linear increase shows several periods of sharply differentiated rate associated with form change of the embryo, occurring, $a$ ) during cleavage and gastrulation; $b$ ) during the formation of the embryonic axis, the formation and closure of the medullary folds; $c$ ) during the formation of the head; d) during the formation and elongation of the tail and the straightening of the body axis; $e$ ) from this period to that of hatching, and, finally, $f$ ) from the period of hatching to metamorphosis; this latter is the first part of the typical sigmoid phase of growth.

7. Hatching occurs at a critical period in the form relations of the salamander. Before hatching, the intracellular yolk deposit is a factor which demands a constant reorganization of the relationships between length and volume. After the period of hatching, the length-volume relation is expressed by a formula, which suggests that, in spite of changes in form, the relation between length and volume is apparently that of a regular object. This character of form control seems to be identical for a number of other developing animals.

\section{LITERATURE CITED}

ADolpH, E.F. 1927 Changes in the physiological regulation of body volume in Rana pipiens during ontogeny and metamorphosis. J. Exp. Zoöl., vol. 47 , pp. $179-195$.

Charke, S. F. 1880 The development of Amblystoma punctatum. Stud. Biol. Lab. Johns Hopkins Univ., vol. 2, pp. 105-125.

DEMPSTER, W. T. 1930 The growth of larvae of Ambystoma maculatum under natural conditions. Biol. Bull., vol. 58, pp. 182-192.

ExCleshyMer, A. C. 1895 The early development of Amblystoma, with observations on some other vertebrates. J. Morph., vol. 10, pp. 343-418.

GORTNER, R. A. 1932 The role of water in the structure and properties of protoplasm. Ann. Rev. Biochem., vol. 1, pp. 21-54.

Harrison, Ross G. 1929 Correlation in the development and growth of the eye studied by means of heteroplastic transplantation. Arch. f. Entwmeeh. d. Org., Bd. 120 (Spemann Festschrift). Bd. 5, S. 1-55. 
Nemdham, J. 1931 Chemical embryology. Cambridge Univ. Press, 3 vols. (esp. pp. 1669-1678).

Рatch, E. M. 1927 Biometric studies upon development and growth in Amblystoma punetatum and A. tigrinum. Proc. Soc. Exp. Biol. and Med., vol. 25 , pp. 218-219.

PIErsol, W. H. 1929 Pathological polyspermy in eggs of Amblystoma jeffersonianum (Green). Trans. Roy. Canad. Inst., vol. 17, p. 71.

SChaPeR, A. 1902 Beiträge zur Analyse des thierischen Wachstums. Arch. f. Entwmech. d. Org, Bd. 14, S. 307-400.

Stone, L. S. 1930 Heteroplastic transplantation of eyes between the early larvae of two species of Amblystoma. J. Exp. Zoöl., vol. 55, pp. 193-254.

Thompsos, D'ARcy W. 1917 Growth and form. Cambridge Univ. Press, p. 17.

WILSON, ChAS. B. 1897 Experiments on the early development of the amphibian embryo under the influence of Ringer and salt solution. Arch. f. Entwmech. d. Org., Bd. 5, S. 615-648. 